\title{
Linfohistiocitosis hemofagocítica asociada a síndrome de Behçet en una paciente con antecedente de artritis reumatoide
}

\author{
Hemophagocytic lymphohistiocytosis associated \\ with Behçet's syndrome in a female patient with a \\ history of rheumatoid arthritis
}

\author{
Juan Carlos Soto, Andrés F. Mier, Rawdy Reales, Karen Vibanco, \\ Carlos Barrera, Felipe GonzÁlez • Barranduilla (Colombia)
}

\section{Resumen}

La linfohistiocitosis hemofagocítica puede aparecer como complicación por hiperreactividad inmune en contexto de pérdida de tolerancia a estructuras propias como en las colagenopatías. Se presenta el caso de una mujer de 62 años de edad, con antecedente de artritis reumatoide, quien reúne criterios diagnósticos para enfermedad de Behçet. Tras complicaciones hematológicas y realización de estudios complementarios se documentan fagocitos con hiperreactividad medular como causa de citopenias, generando el diagnóstico de linfohistiocitosis hemofagocítica. Con el presente caso se pretende resaltar la asociación de alteraciones hematológicas e inflamatorias en pacientes con enfermedad autoinmune.

Palabras clave: linfohistiocitosis hemofagocítica, artritis reumatoide, síndrome de Behçet, autoinmune, virus herpes simple.

\begin{abstract}
Hemophagocytic lymphohistiocytosis can appear as a complication due to immune hyperreactivity in the context of loss of tolerance to own structures as in collagen diseases. The case of a 62-year-old woman with a history of rheumatoid arthritis who meets diagnostic criteria for Behçet's disease is presented. After haematological complications and complementary studies, phagocytes with medullary hyperreactivity are documented as a cause of cytopenias, generating the diagnosis of hemophagocytic lymphohistiocytosis. With the present case, it is intended to emphasize the association of hematological and inflammatory alterations in patients with autoimmune disease.

Key words: hemophagocytic lymphohistiocytosis, rheumatoid arthritis, Behçet syndrome, autoimmune, herpes simplex virus.
\end{abstract}

Dr. Juan Carlos. Soto B.: Residente Tercer Año Medicina Interna, Universidad Libre; Dres. Andrés F. Mier B., Rawdy Reales R., Karen Vibanco P.: Residentes Segundo Año Medicina Interna. Universidad Libre; Dr. Carlos Barrera G.: Internista. Coordinador del Programa de Medicina Interna Universidad Libre; Dr. Felipe González C.: Jefe de Medicina Interna Organización Clínica General del Norte - OCGN. Barranquilla (Colombia).

Correspondencia: Dr. Juan Carlos Soto. Barranquilla (Colombia).

E-mail: juanksoto1@hotmail.com

\section{Introducción}

El síndrome de Behçet (SB) es una enfermedad crónica y recidivante, inflamatoria multisistémica, de carácter autoinmune $(1,2)$, cuya principal lesión anatomopatológica es una vasculitis, perteneciente al grupo vaso variable (3); desencadenada por interacción de factores exógenos en individuos genéticamente predispuestos (4).

Usualmente ocurre entre la tercera y cuarta década de la vida, siendo raro en la pubertad y en personas mayores de 50 años. Afecta por igual ambos géneros, pero es más grave en hombres $(1,5)$.
Es considerada una entidad rara en algunos países de Europa y en Estados Unidos (6); su distribución geográfica es coincidente con lo que anteriormente se denominaba ruta de la seda, donde se destacan algunos países de Asia Central, del Lejano Oriente y Turquía, siendo este último el de mayor prevalencia con reportes que oscilan entre 20 - 421 casos/100 000 habitantes $(1,7)$.

En Colombia, la única serie reportada se publicó en la Revista Colombiana de Reumatología en el año 2009, donde se identificó una cohorte de 20 pacientes, con predominio en mujeres en relación $15 / 5$ respecto al género masculino $(1,9)$. 
El desarrollo de la enfermedad es desconocido, pero se relaciona con alteraciones genéticas, principalmente a nivel del antígeno leucocitario humano HLA-B51 del complejo principal de histocompatibilidad clase I, que al interactuar con agentes infecciosos como el virus del herpes simple (VHS), desencadena la respuesta inflamatoria típica del síndrome (10).

Por otro lado, la linfohistiocitosis hemofagocítica (LHH) constituye un síndrome clínico inflamatorio, amenazante para la vida (11), causado por hipercitoquinemia severa debido a una respuesta inmune altamente estimulada e incontrolada; caracterizado por fiebre, hepatoesplenomegalia, citopenias y hallazgo de macrófagos activados en órganos hematopoyéticos $(12,13)$.

Se considera una enfermedad rara, con una incidencia mundial desconocida, que puede atribuirse a que en muchos casos se hace patológicamente evidente solo hasta el momento de la autopsia (14).

La LHH según la causa se clasifica en primaria y secundaria (reactiva), siendo esta última la forma de presentación mss común en el adulto, la cual requiere de la interacción de uno o más factores desencadenantes en un individuo con una condición predisponente.

Dentro de los factores predisponentes se destacan las neoplasias hematológicas, seguido en orden de frecuencia por enfermedades autoinmunes como lupus eritematoso sistémico (LES) o la enfermedad de Still y en menor porcentaje artritis reumatoide (AR) y vasculitis sistémicas como el SB. Los factores desencadenantes pueden ser no infecciosos o infecciosos, destacándose dentro de este último grupo la etiología viral, siendo el virus del Epstein Barr (VEB) el de mayor porcentaje de presentación, seguido del virus del herpes simple (VHS) y otros tipos de virus. (15).

De acuerdo con la naturaleza autoinmune del SB y la LHH, resulta consecuente el uso de terapia inmunosupresora, teniendo los glucocorticoides indicación de primera línea en dosis altas al inicio del cuadro, suspendiéndose de forma progresiva según la necesidades del paciente $(15,16)$.

A continuación se presenta el caso de una paciente en la séptima década de la vida, con antecedentes de

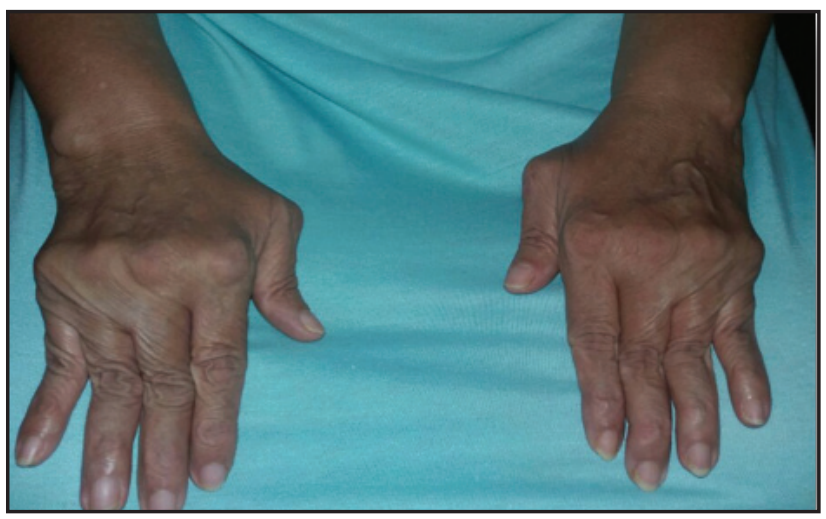

Figura 1. Deformidades de fase avanzada de artritis reumatoide.
AR, quien desarrolla SB y LHH, desencadenados por el VHS y VEB.

\section{Presentación del caso}

Se trata de paciente femenino, 62 años de edad, raza mestiza, con antecedentes de AR hace 17 años, tratada con metotrexate hasta cuatro meses previos a su ingreso y prednisolona, quien consulta por cuadro clínico de dos meses de evolución caracterizado por lesiones ulcerosas, fondo limpio, bordes irregulares, dolorosas en muslo derecho y aftas orales; concomitante describe fiebre subjetiva intermitente; tratada con terapia antibiótica oral, sin resolución del cuadro. Cuatro semanas previas al ingreso aparecen úlceras en región genital e inguinal, presenta deterioro del estado general, consultando a institución local donde realizan manejo empírico, toman muestras para exámenes y dan egreso. Ante persistencia del cuadro consulta a nuestra institución.

Se destaca que desde hace tres años, cada tres meses, presentaba úlceras orales y lesiones ulcerosas de características similares a las descritas, en abdomen, glúteos y muslos.

Al examen físico se evidencia deformidades típicas de la fase avanzada de AR como desviación cubital, pulgar en $\mathrm{Z}$ y dedos en cuello de cisne (Figura 1); en piel y mucosas se documenta prueba de patergia positiva, lesiones de bordes irregulares, tejido fibrinoide, sin secreciones, en genitales mayores y en muslos en número de tres (Figura 2).

Se realizan estudios paraclínicos y se inicia terapia antibiótica de amplio espectro, sin documentar mejoría del cuadro.

Dentro los resultados se encuentra hemograma con leucopenia (3040 células/mm3) y porcentaje de neutrófilos de $1 \%$, Niveles de hemoglobina en $10.4 \mathrm{gr} / \mathrm{dL}$, cifras que descendieron durante su estancia hospitalaria hasta valores de $9.6 \mathrm{gr} / \mathrm{dL}$, valor de ferritina $1045 \mu \mathrm{g} / \mathrm{mL}$, proteína C Reactiva (PCR) y velocidad de sedimentación globular (VSG) positivos, factor reumatoideo positivo, complemento sérico, C4, ligeramente consumido $(7.4 \mathrm{mg} / \mathrm{dL}), \mathrm{P}-\mathrm{ANCA}$ positivo 1/40 diluciones, además serología IgG para VEB, VHS tipo 1 y tipo 2, positivos; VDRL, FTA ABS, no reactivos; triglicéridos y fibrinógeno normales.

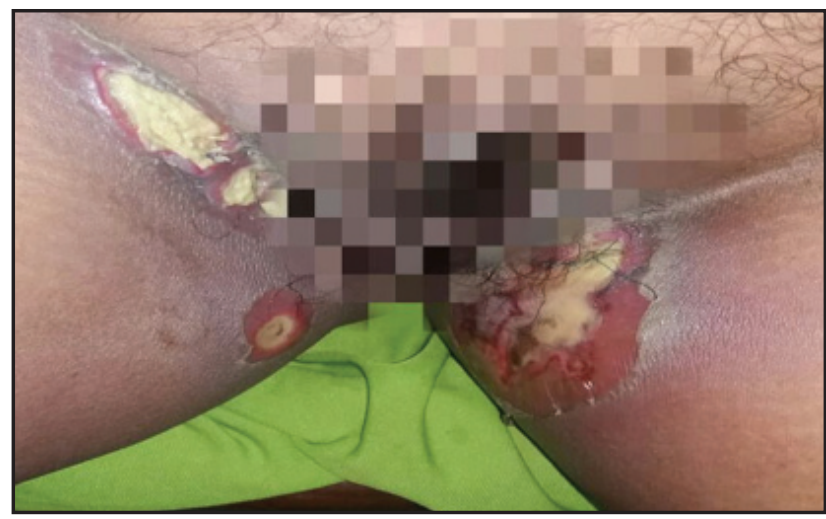

Figura 2. Ulceras inguinales. 
Aspirado de médula ósea reporta ausencia de células malignas y evidencia histiocitos fagocitando glóbulos rojos, plaquetas y neutrófilos (Figura 3).

Reporte de biopsia ambulatoria de muslos, incluye como diagnósticos diferenciales, SB, enfermedad de Crohn metastásica y enfermedad infecciosa por treponema.

De acuerdo con todo lo anterior se plantean diagnósticos de:

1. Neutropenia febril alto riesgo (índice mascc 19, duración $>7$ días. RAN: 30/mm3) secundario a:

2. Linfohistiocitocis hemofagocítica secundaria a síndrome de activación macrofágica por enfermedades autoinmunes.

3. Vasculitis de vaso variable, tipo enfermedad de Behçet.

4. Artritis reumatoide

5. Infección crónica por virus del herpes 1,2 y virus Epstein Barr.

Dado la ausencia de respuesta al tratamiento antibiótico, los diagnósticos planteados y considerando su carácter autoinmune, se decide iniciar pulsos con metilprednisolona $1 \mathrm{gr}$ IV/día por tres días, acompañado de corticoides tópicos de alta potencia, evidenciando al tercer día de inicio de tratamiento mejoría considerable a nivel de lesiones, documentada por disminución del tamaño y tejido fibrinoide e incluso desaparición de algunas úlceras (Figura 4); lográndose también, aumento del recuento absoluto de neutrófilos superando 500 células $/ \mathrm{mm}^{3}$.

Paciente con evolución satisfactoria, mejoría de paraclínicos y ausencia de fiebre durante más de siete días, por lo que, luego de tres semanas de estancia hospitalaria, se da egreso con seguimiento y tratamiento ambulatorio.

\section{Discusión}

La estructura del pensamiento lógico que nos permite llegar a los diagnósticos planteados y decidir el tratamiento instaurado, se soporta en dos aspectos fundamentales; el primero, consiste en el síntoma cardinal, que está representado por la aftosis compleja, la cual se entiende como presencia de tres o más aftas orales, bien sea, acompañadas de aftas genitales, que generalmente se presentan en brotes prolongados que pueden llegar a ser continuos. Ante la presencia de una aftosis compleja o bipolar, el primer diagnóstico a plantear debe ser SB luego de descartar diagnósticos diferenciales $(5,17)$.

De acuerdo con el hallazgo clínico y teniendo en cuenta el reporte de biopsia que incluye SB y diagnósticos diferenciales, se procede a descartar o confirmar dichas entidades.

En primera medida, se descarta infección por treponema mediante resultados negativos de VDRL y FTA ABS, luego se considera la premisa que toda aftosis bipolar debe hacer sospechar el diagnóstico de SB, por lo que se aplican los criterios clínicos para dicha enfermedad, que representan la principal herramienta diagnóstica.

Los criterios fueron propuestos desde el año 1990 por el grupo de estudio internacional para la enfermedad de Behçet

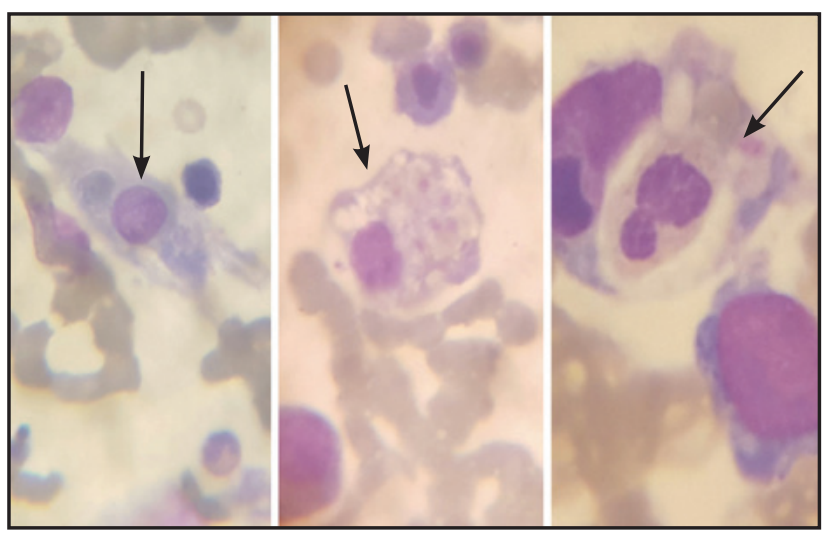

Figura 3. Aspirado médula ósea, histiocitos fagocitando glóbulos rojos, plaquetas y neutrófilos (flechas) (Cortesía Dr José Marún hematólogo).

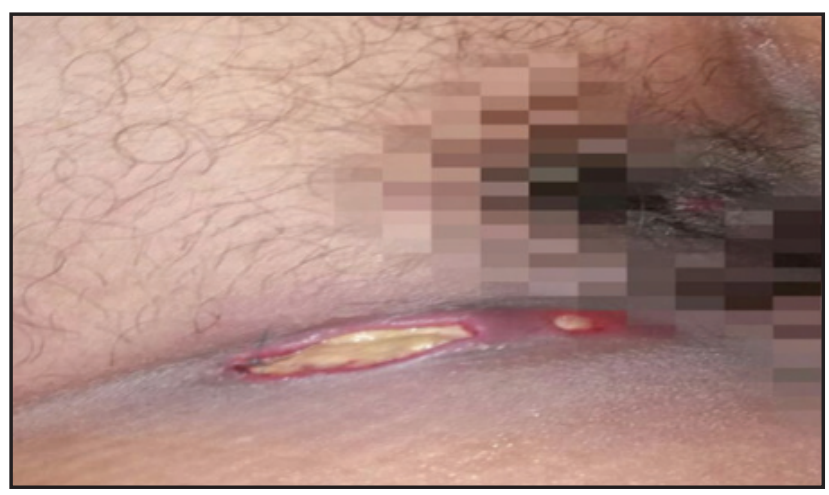

Figura 4. Mejoría de úlceras inguinales.

y establecen realizar el diagnóstico cuando se presentan úlceras orales recurrentes y dos o más de los siguientes criterios: úlceras genitales recurrentes, lesiones oculares, lesiones cutáneas o prueba de patergia positiva $(18,19)$. Dichos criterios tienen una sensibilidad de $91 \%$ y especificidad de $96 \%$ (5). Se resalta que la paciente cursó con lesiones orales recurrentes, lesiones genitales y prueba de patergia positiva cumpliendo los criterios diagnósticos.

El segundo aspecto fundamental en la secuencia que permite establecer los diagnósticos, se soporta en un hallazgo de laboratorio, representado en el hemograma y que hace referencia a la bicitopenia (neutropenia severa y anemia), lo cual obliga a establecer la etiología de dicha alteración realizando estudios de extensión, dentro de los cuales se obtiene niveles de ferritina $>1000 \mu \mathrm{g} / \mathrm{mL}$ y presencia de hemofagocitosis en medula ósea; esto, sumado a la presencia de temperatura mayor de $38.5^{\circ} \mathrm{C}$ durante mas de siete días, así como la alteración de líneas celulares hematológicas, permite revisar los criterios de la sociedad de la histiocitosis, actualizados en el año 2004, para definir una enfermedad denominada linfohistiocitosis hemofagocítica, los cuales consideran el diagnóstico con la presencia de cinco de los siguientes ocho aspectos: fiebre $>0=38.5^{\circ} \mathrm{C}$, esplenomegalia, citopenias, hipertrigliceridemia y/o hipofibrinogenemia, 
hemofagocitosis en médula ósea, ganglios o bazo, niveles bajos o ausencia de actividad de células Natural Killer (NK), Ferritina $>500 \mu \mathrm{g} / \mathrm{L}, \mathrm{CD} 25$ soluble $>2400 \mathrm{U} / \mathrm{mL}$ (20). De los criterios mencionados, la paciente presenta cuatro, atribuible a una fase inicial de LHH y coincide con descripciones de la literatura que afirman que en muchas ocasiones pueden no aparecer las manifestaciones completas en la presentación inicial (21), además, algunos criterios como la medición de NK sólo pueden completarse en laboratorios certificados (11).

La LHH secundaria constituye una entidad reactiva que requiere factores predisponentes, dentro los que se destacan en el caso presentado la AR y SB, sin poder atribuir la predisposición de forma exclusiva a una de las dos enfermedades; pero dicha predisposición no es suficiente y requiere de agentes precipitantes, dentro de los cuales señalamos en la paciente, la infección por VEB y VHS.

El tratamiento de ambas entidades, requiere del control de los factores predisponentes y desencadenantes, así como también la administración de inmunosupresores, por lo que la administración de corticoides en pulsos tienen evidencia demostrada, lo cual permitió tomar la decisión de administrarlos, logrando documentar una notoria mejoría.

\section{Conclusión}

El SB y La LHH son consideradas raras en algunos lugares del mundo, pero esto podría ser por subdiagnóstico y no por baja prevalencia.

La AR y SB constituyen factores predisponente para LHH, mientras que el VHS y VEB son factores desencadenantes; por otro lado, el VHS puede desencadenar la respuesta inflamatoria característica del SB.

Nuestro caso representa una paciente con factores predisponentes, expuesta a factores desencadenantes, quien desarrolla EB y LHH, que al recibir tratamiento con pulsos de corticoides tiene respuesta favorable, tal como se describe en la literatura mundial.

\section{Referencias}

1. Sebahattin Yurdakul. Vedat Hamuryudan. Hasan Yazici. Behçet syndrome. Marc C. Hochberg. Rheumatology. Sixth edition. Elsevier. 2015. 1328-1333.

2. Tsuyoshi Sakane, Mitsuhiro Takeno, Noboru Suzuki and Goro Inaba. Behçet's disease. $N$ engl j med. october 21, 1999 volume 341 number 17.

3. C. Campos Fernández, A. Baixauli Rubio, et al. Enfermedad de Behçet. Miguel A Belmonte. Enfermedades reumáticas actualización SVR. II edición. España.Pág. 495-516.

4. Jenaro Graña Gil. Aspectos clínicos novedosos en la enfermedad de Behçet. Reumatol Clin. 2008; 4 Supl 1: S50-5.

5. L. Vaillant, M. Samimi, D. Parent. Aftas, aftosis, enfermedad de Behçet. EMC Dermatología. Vol. 50, numero 2, junio 2016.

6. Pietro Leccesea, Yusuf Yazicib, and Ignazio Olivieri. Behcet's syndrome in nonendemic regions. Curr Opin Rheumatol 2017, (29): 12-16.

7. Fereydoun Davatchi, Cheyda Chams-davatchi, et al. Behcet's Disease: Epidemiology, Clinical Manifestations, and Diagnosis. Exp Rev Clin Immun. June 2016.

8. Toro A M, Pinto L F, Velásquez C J, Márquez J D et al. Enfermedad de Behcet. Rev. Colomb. Reumatol. Vol. 16 D, Marzo 2009, pp. 97-111.

9. Toro A M, Pinto L F, Velásquez C J, Márquez J D et al. Enfermedad de Behcet: experiencia en una cohorte de pacientes colombianos. Rev Colomb Reumatol. Vol. 16 No. 1, Marzo 2009, pp. 33-45 .

10. Erkan Alpsoy. Behcet's disease: A comprehensive review with a focus on epidemiology, etiology and clinical features, and management of mucocutaneous lesions. J Dermat. 2016; (43): 620-632.

11. Alexandra H. Filipovich, MD, Shanmuganathan Chandrakasan. Pathogenesis of Hemophagocytic Lymphohistiocytosis. Hematol Oncol Clin N Am. (2015).

12. Anna Hayden, Sujin Park, et al. Hemophagocytic syndromes (HPSs) including hemophagocytic lymphohistiocytosis (HLH) in adults: A systematic scoping review. Blood Rev. 30 (2016): 411-420.

13. Gritta E. Janka, Kai Lehmberg. Hemophagocytic syndromes, an update. Blood Rev. 28 (2014): 135-142.

14. Melissa R George. Hemophagocytic lymphohistiocytosis: review of etiologies and management. J Blood Med. (2014): 5.

15. Manuel Ramos-Casals, Pilar Brito-Zerón et al.Adult haemophagocytic síndrome Lancet Vol 383; (383): 1503-16 April 26, 2014.

16. Gianluigi Mazzoccoli,Angela Matarangolo, et al. Behçet syndrome: from pathogenesis to novel therapies. Clin Exp Med. Published online december 2014.

17. Gabriel Riera Matute, Elena Riera Alonso. La aftosis oral recurrente en Reumatología. Reumatol Clin. 2011; 7323-328.

18. Anonymous. International study group for Behçet's disease. Criteria for diagnosis of Behçet's disease. Lancet. 1990; (335): 1078-80.

19. Fereydoun Davatchi. Diagnosis/Classification Criteria for Behcet's Disease. Patholo Rese Inter. Volume 2012 Article ID 607921.

20. Jan-Inge Henter, AnnaCarin Horne et al. HLH-2004: Diagnostic and Therapeutic Guidelines for Hemophagocytic Lymphohistiocytosis. Pediatr Blood Cancer 2007; (48): 124-131.

21. Alison M. Schram and Nancy Berliner. How I treat hemophagocytic lymphohistiocytosis in the adult patient. Blood. 7 May 2015, Vol 125, Number 19. 